\title{
A CYTOCHEMICAL METHOD FOR INDOXYL ACETATE ESTERASE
}

\author{
TAKAO KAWASHIMA
}

\section{Department of Surgery, Okayama University Medical School, Okayama}

\author{
Received for Publication December 3, 1968.
}

\begin{abstract}
An azo-coupling cytochemical method for indoxyl acetate esterase was reported employing indoxyl acetate as the substrate and tetrazotized BAXD as the coupler which was more penetrable into unfrozen diced tissue fragments than hexazotized pararosanilin.

Both the membranous activity in the wall of cytoplasmic tubular canaliculi and in the nuclear membrane and the non-membranous activity in lysosomes were clearly observed in proximal segment cells of rat kidney electronmicroscopically by this method.
\end{abstract}

Recently, Seligman et al. (7) and Plapinger et al. (6) have successfully demonstrated the cytochrome oxidase activity by osmiophilic polymer formation. The new reaction, using $\mathrm{DAB}$ or $\mathrm{BAXD}$ as the substrate, produced fine distribution in non-droplet form in contrast to the lipid soluble Nadi dyes.

The BAXD, N,N'-bis (4-aminophenyl)-1, 3-xylylenediamine, has two amines which are capable of being azotized, and tetrazotized BAXD was prepared by treating with hydrochloric acid and sodium nitrite. The tetrazonium was employed in attempt to induce several esterase reactions using beta-naphthyl acetate, naphthol AS acetate, and indoxyl acetate which composed an osmiophilic pigment as well as the most fine localization of all. On the other hand, in 1966 an excellent azoindoxyl method has been developed by Holt and Hicks (5) using hexazotized pararosanilin, which was not so penetrable into tissue that they had to use frozen sections in 30 microns thickness for the cytochemical stain for electron microscopy. The tetrazotized BAXD gave a solution to the penetration problem. In the present method, diced fragments of unfrozen tissue were used for the esterase stain in order to preserve precise cytological structure.

\section{MATERIAL AND METHODS}

Fresh rat kidney was cut in round slices with a sharp razor blade and fixed in $4 \%$ paraformaldehyde solution containing $0.05 M$ phosphate buffer at $\mathrm{pH} 7.0$ and $5 \%$ sucrose at $4{ }^{\circ} \mathrm{C}$ overnight. The fixed tissue slices were washed with chilled physiological saline for $10 \mathrm{~min}$, and stored in the same solution at $4^{\circ} \mathrm{C}$ for 2 to $24 \mathrm{hrs}$. One of the slices was cut in a cryostat and used for microscopic esterase reaction. The others were diced with sharp razor blade into fragments no longer than $1.0 \mathrm{~mm}$ in any dimension. The diced blocks were incubated in the medium at $0^{\circ} \mathrm{C}$ to $10^{\circ} \mathrm{C}$ for 100 to $200 \mathrm{~min}$, then wahsed in chilled physiological saline, and kept for an hour.

The medium used was composed of: indoxyl acetate in $0.1 \mathrm{ml}$ of acetone 
$0.2 M$ phosphate buffer, $\mathrm{pH} 7.0$

Stained tissues were osmicated in 1 to $2 \%$ osmium tetroxide solution at $37^{\circ} \mathrm{C}$ for 100 min, washed, dehydrated and embedded in epon by the routine method. For light microscopic study, the incubating time could be shorter than that mentioned above and stained sections were mounted in permount after the osmication.

\section{RESULTS}

The azodye was readily soluble in alcohol before osmication, but it was insoluble in any of the solvents used through electron microscopic procedures and was electron opaque after the osmication.

Under light microscope, the pigment was of an orange color and densely located in cytoplasmic droplets and moderately in whole cytoplasm of proximal segment cells of the kidney cortex in spite of being negative in distal segment cells (Fig. 5). A greater accuracy could be expected by employing thick section technique before thin sectioning of the tissue embedded in epon for electron microscopy. The thick section revealed a satisfactory penetration in small diced fragments, that was about two segments thick (Fig. 6).

In electron microscope, the electron opaque azo indoxyl-osmium polymer was localized in lysosomes, cytoplasmic tubular canaliculi which might be the smooth-surfaced endoplasmic reticulum, and the nuclear membrane. The pigment deposition was neither crystalline nor granular but electron-dense and was located exactly at the sites of esterase activity. The pictures displayed non-membranous localization of esterase in lysosomes in various degrees. Branching tubular canaliculi showing positive esterase activity in the wall run throughout the cytoplasm occurring between bases of microvilli to the basement membrane. The

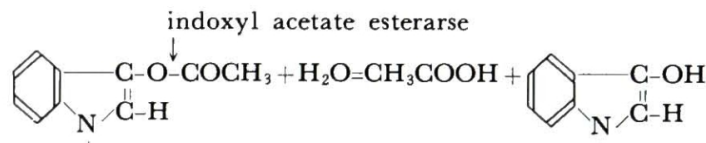

$\mathrm{H}$

$\mathrm{H}$

FIG. 1. Indoxyl acetate is hydrolyzed by indoxyl acetate esterase.

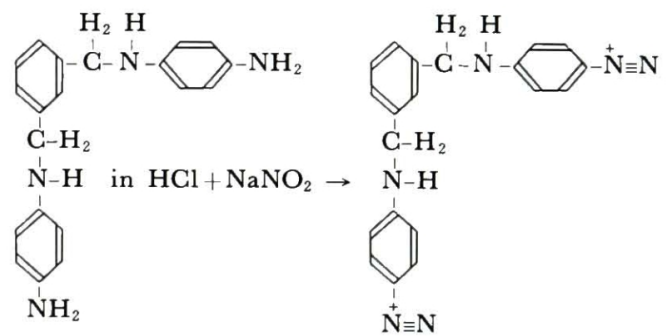

FIG, 2. Tetrazotized BAXD is prepared at low temperature. 


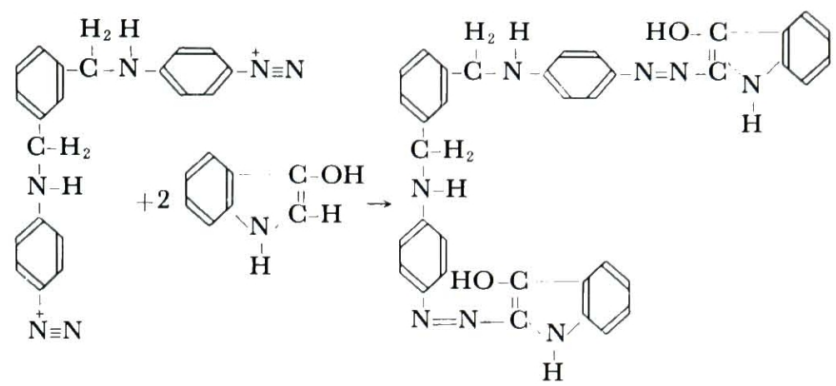

Fig. 3. Azoindoxyl coupling reaction

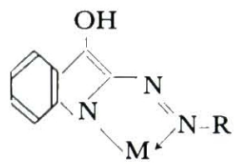

Fig. 4. Chelating reaction: $M$, osmium

canaliculi were often observed around mitochondria, vesicles and other organelles, branching out and anastomosing with the nuclear membrane that was also positive for esterase, lysosomes and probably a few ends of lamellae in the Golgi complex. The Golgi complex was negative except in some portion of the lamellae. The other organelles in the cytoplasm were absolutely negative (Figs. 7, 8).

\section{DISGUSSION}

Barrnett and Seligman(7) first proposed the use of indoxyl acetate as a histochemical substrate for the demonstration of esterases, such as lipase, non-specific esterase and cholinesterases in 1951 (Fig. 1). In the method, enzymatic hydrolysis of indoxyl acetate occurred resulting in the formation of an insoluble precipitation of indigo. This method was further improved by Holt (3) and Holt and Withers (4).

Recently, Seligman, Hanker and coworkers $(2,8,9)$ have investigated esterase cytochemistry for electron microscopy employing osmiophilic reagents, and have clarified that the final product of the enzyme reaction, osmium black is adequate in demonstrating the sites of enzyme activity for both light and electron microscopy. In 1966, Holt and Hicks (5) have developed an osmicating azoindoxyl method that showed an excellent location of esterase distribution after osmicating treatment in electron microscope. They used hexazotized pararosanilin and indoxyl acetate to form an azoindoxyl composing osmium-containing network in the enzyme localization by treating with osmium tereoxide and claimed that the enzyme reaction took place in the rough-surfaced endoplasmic reticulum and the nuclear envelope as well as in cytoplasmic droplets.

However, since hexazonium pararosanilin is hardly penetrable in unfrozen tissue, the author used tetrazotized BAXD prepared from BAXD as a substitute for hexazotized pararosanilin in this study (Fig. 2). BAXD was originally produced as substrate for the cytochrome oxidase reaction by Plapinger et al. (6) and in their 


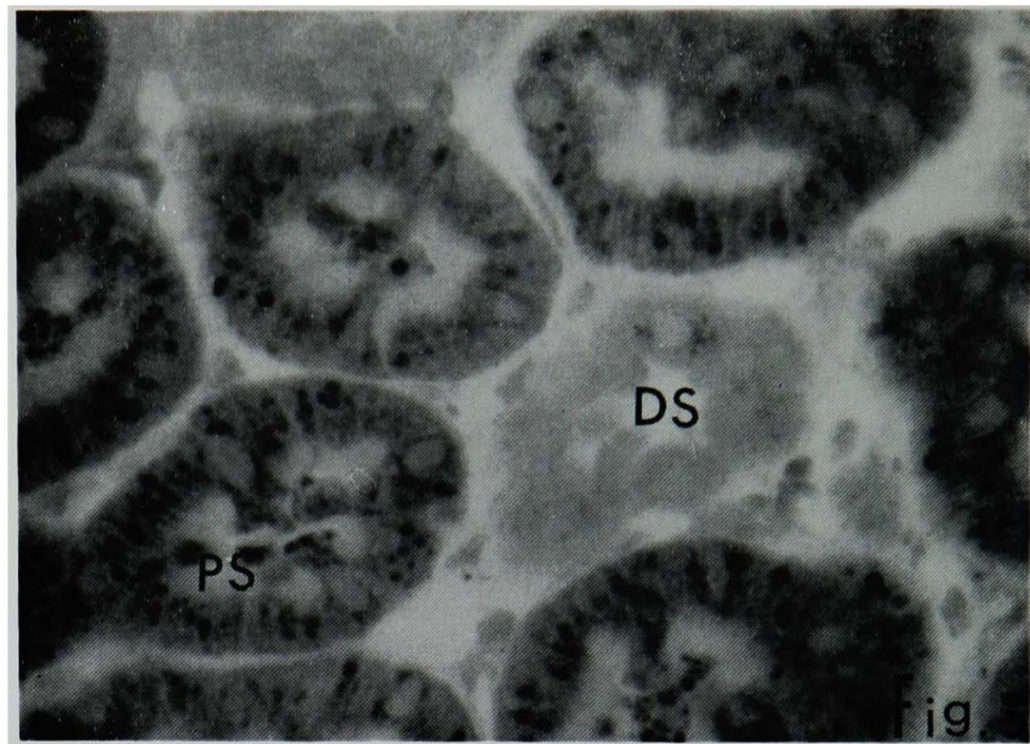

Fig. 5. Esterase reaction in a frozen section under light microscope, $\times 1200$ PS, proximal segment; DS, distal segment

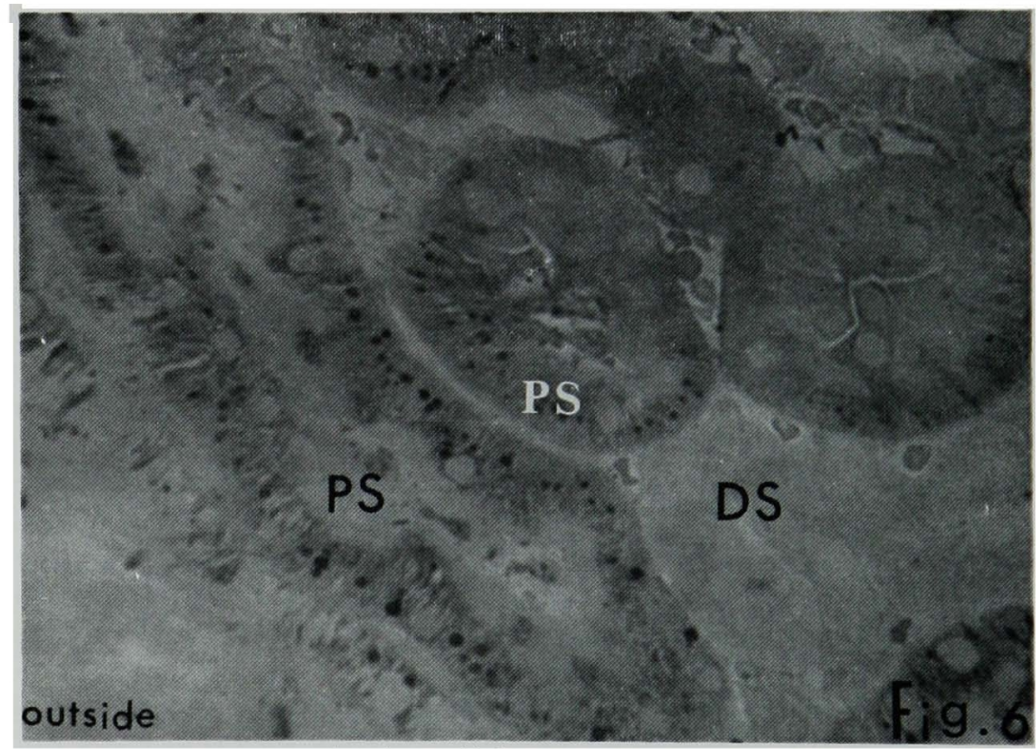

Fig. 6 Esterase reaction in a thick epon section of unfrozen block under light microscope. $\vee 1200$ Note the penetration of the incubating medium, that is about two segments thick from surface of the block. 

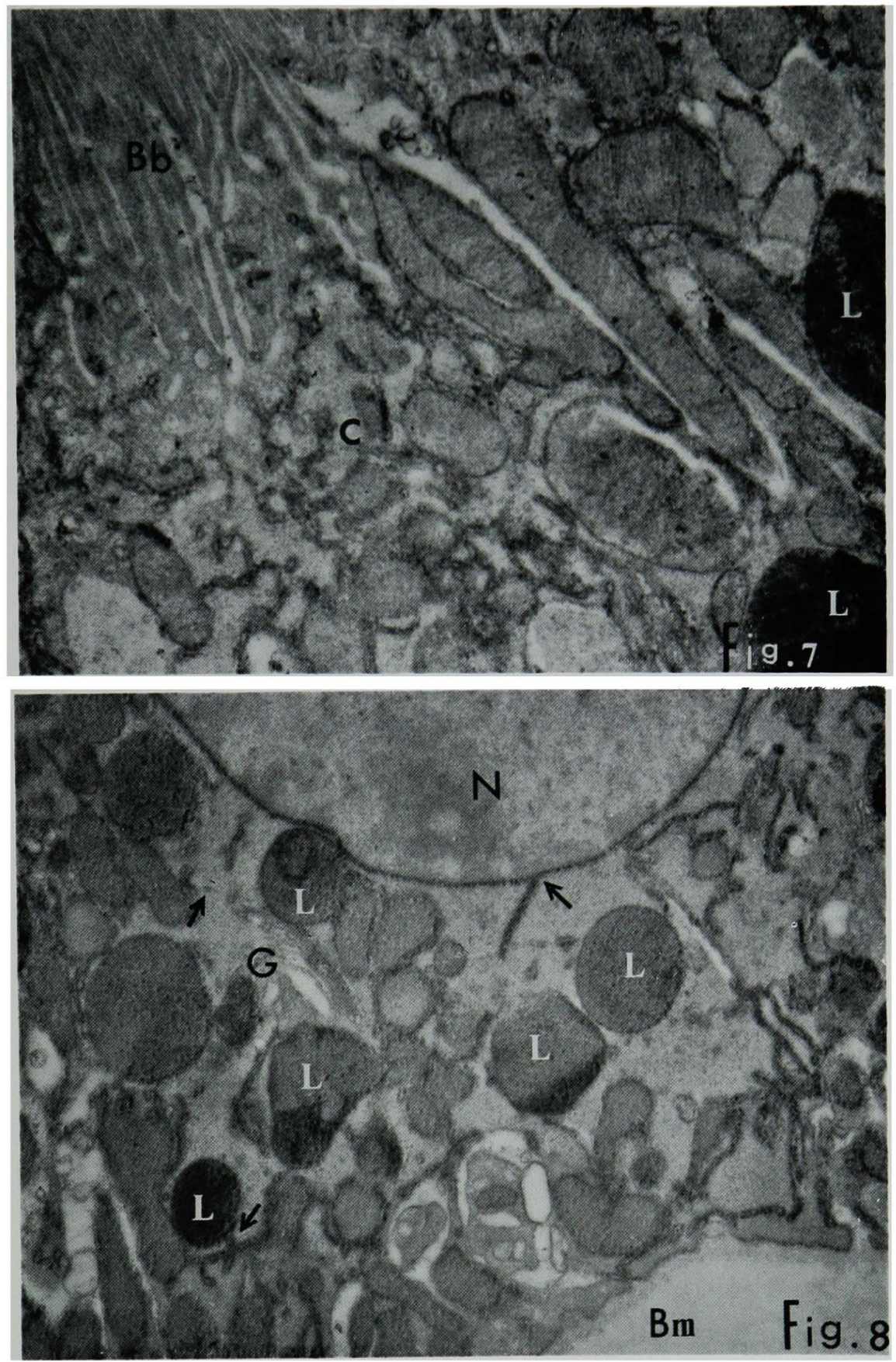
preliminary experiment they found that marked penetration of BAXD into tissue as in the case with DAB (diaminobenzidine). The tetrazotized BAXD was substituted in order to perform a similar indoxyl reaction in unfrozed tissue, although Holt and Hicks (5) described that dyes formed from simpler diazonium or tetrazonium salts and indoxyl acetate were less suitable for an electron microscopic cytochemistry because of extraction of the pigments from tissue after osmium exposure during the embedding procedure. Stability of the osmium-azoindoxyl polymer which was procuded by osmicating treatment was exactly confirmed in the preliminary experiments. Chelating reaction might have occurred in tissue as Fig. 4 as osmium tetroxide is reduced in tissue during osmication, and osmium linked network, polymer was formed as described by Holt and Hicks (5). In the present study the precise location revealed two different esterases; one was lysosomal nonmembranous esterase and another membranous one in the nuclear membrane and wall of cytoplasmic tubular canaliculi which were perhaps the smooth-surfaced endoplasmic reticulum. This complete process of the tubuler canaliculi has not been demonstrated so exactly by plain electron microscopy up to the present.

Pattern of some lysosomal reactions in which esterase activity was partially demonstrable probably indicates that the non-membranous estearse enzyme was in gel.

In addition to the technical development as mentioned above, a cytochemical suggestion on reabsorption mechanism of ester compounds in urine was presented. Urine perhaps passes through the cytoplasmic tubular canaliculi and lysosomes in proximal segment cells of the kidney and hydrolized compounds might be absorbed in cytoplasm after hydrolyzing the urinary esters by both membranous and non-membranous esterases. The reabsorption is presumably performed by osmotic infiltration, because no pinocytosis was noticed in the wall of the tubular canaliculi and of lysosomes.

\section{ACKNOWLEDGMENT}

The author wishes to acknowledge favor of Prof. Seligman and Dr. Plapinger who presented the invaluable BAXD to me.

\section{REFERENCES}

1. Barrnett, R.J. and Seligman, A.M.: Histochemical demonstration of esterases by production of indigo. Science $114 ; 579,1951$

FIG. 7. and 8. Electron microscopic pictures without any electron stain They are prepared from the same block as described in Fig. 6.

Fig. 7. shows an apical part of a proximal segment cell. $\times 15600$ Reaction product is observed in lysosomes and in the wall of cytoplasmic tubular canaliculi. L, lysosome; $\mathrm{C}$, cytoplasmic tubular canaliculi; $\mathrm{Bb}$, brush border

FIG. 8. displays a basal part of a cell within proximal segment. $\times 13500$ Nuclear envelope is also positive for the enzymatic reaction. Bm, basement membrane; $\mathrm{N}$, nucleus; $\mathrm{G}$, Golgi complex; Arrow marks, tubular communications with nuclear membrane, lysosome and probably Golgi complex 
2. Hanker, J.S., Seligman, A.R., Weiss, L.P., Ueno, H., Bergman, R.A., and Seligman, A.M.: Osmiophilic reagents: New cytochemical principle for light and electron microscopy. Science 146; 1039, 1964

3. Holt, S.J.: A new principle for the histochemical localization of hydrolytic enzymes. Nalure 169; 271,1952

4. Holt, S.J. and Withers, R.F.J.: Cytochemical localization of esterases using indoxyl derivatives. Nature 170;1012, 1952

5. Holt S.J. and Hicks, R.M.: The importance of osmiophilia in the production of stable azoindoxyl complexes of high contrast for combined enzyme cytochemistry and electron microscopy. J. Cell Biol. 29; 361, 1966

6. Plapinger, R.E., Linus, S.L., Kawashima, T., Deb, C., and Seligman, A.M.: Preparation and structure-activity relationship of reagents for cytochrome oxidase activity: Potential for light and electron microscopy. Histochemie 14; 1, 1968

7. Seligman, A.M., Karnovsky, M.J., Wasserkurg, H.L., and Hanker, J.S.: Nondroplet ultrastructural demonstration of cytochrome oxidase activity with a polymerizing osmiophilic reagent, diamino benzidine (DAB). J. Cell Biol. 38; 1, 1968

8. Seligman, A.M.: Some reagent trends and advances in enzyme histochemistry. Sinai Hospital J. $12 ; 73,1965$

9. Seligman, A.M., Ueno, H., Wasserkurg, H.L., and Hanker, J.S.: Esterase method for light and electron microscopy via the formation of osmiophilic diazothioethers. Ann. Histochm. 11; 115, 1966 